\title{
Properties of Quantum Gain of Coding with Information Criterion by Binary Linear Codes
}

\author{
Yuki Ishida Non-member (Aichi Prefectural University) \\ Shogo Usami Non-member (Meijo University) \\ Tsuyoshi Sasaki Usuda Member (Aichi Prefectural University) \\ Ichi Takumi Member (Nagoya Institute of Technology)
}

Keywords: Quantum information theory, Quantum channel capacity, Superadditivity, Square-root measurement, Quantum gain by coding

In quantum information theory, there is superadditity in capacity of a quantum channel when Shannon (classical) information is transmitted over a quantum channel. Existence of superadditivity is special property in a quantum channel, so it has not been in a classical channel. Recently, clear examples of strict superadditivity for binary pure-state signals with finite codeword length were demonstrated. However, to calculate mutual information with large number of codewords is very difficult because of computational cost. We have shown the analytical solution of mutual information when we use classical linear codes for coding scheme and use square-root measurement as decoding scheme. Therefore, many examples of codes which shows superadditivity in capacity have been given. But the scope of the method has not been clarified.

In the present paper, we show the method can be applied to any binary linear codes. Moreover, we show quantum channel capacity is almost attained in finite codeword length by using approximation to simplex code.

We assume a priori probabilities of all codewords are equal. By using group covariancy of linear codes, we obtained the analytical expression of mutual information as

$$
\begin{aligned}
I_{n}(X ; Y) & =k+\sum_{j=0}^{2^{k}-1} P(j \mid 0) \log P(j \mid 0), \cdots \\
P(j \mid 0)= & \left\{\left(\Gamma_{2^{k}}\right)_{0, j}^{\frac{1}{2}}\right\}^{2} \\
= & \left\{\frac{1}{2^{k}} \sum_{k^{\prime}=0}^{2^{k}-1}(-1)^{w_{\mathrm{H}}\left(j \cdot k^{\prime}\right)}\right. \\
& \left.\sqrt{\sum_{l=0}^{2^{k}-1}(-1)^{w_{\mathrm{H}}\left(k^{\prime} \cdot l\right)}\left(\Gamma_{2^{k}}\right)_{0, l}}\right\}^{2},
\end{aligned}
$$

where $n$ is codeword length, $\Gamma_{2^{k}}$ is the Gram matrix, $2^{k}$ is the number of codewords, $w_{\mathrm{H}}(i)$ denotes the Hamming weight of $i$ in binary notation, and $j \cdot k^{\prime}\left(k^{\prime} \cdot l\right)$ means "AND" operation for each bit when $j\left(k^{\prime}\right)$ and $k^{\prime}(l)$ are represented as binary numbers of $n$-digits.

Proposition : Eqs.(1) and (2) can be applicable to any binary linear code.

By using the above formula, we can compute mutual information with large number of codewords (up to about 1,000,000 codewords). Fig. 1 shows that mutual information

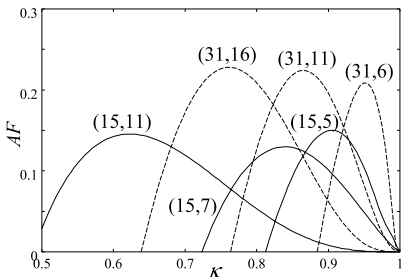

Fig. 1. The achievement factor of quantum gain by primitive $\mathrm{BCH}$ code with codeword length 15 and 31 as functions of $\kappa$.

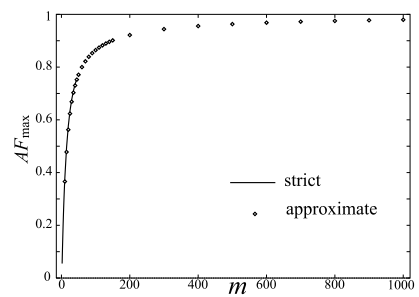

Fig. 2. The maximum achievement factor of quantum gain by simplex code as functions of code scale $m$.

per letter $I_{n}(X ; Y) / n$ and a quantity $A F$ of simplex code and primitive $\mathrm{BCH}$ codes of codeword length 15 and 31. Here, $A F$ is defined as

$$
A F=\frac{I_{n}(X ; Y) / n-C_{1}}{C-C_{1}}, \cdots
$$

which represents how much is superadditivity achieved to $C$. If $A F=0, I_{n}(X ; Y) / n=C_{1}$ and if $A F=1, I_{n}(X ; Y) / n=$ $C$, i.e., the quantum channel capacity is achieved. We also define the maximum value of $A F$ with respect to $\kappa$ : $A F_{\max }=\max _{\kappa} A F$ and show the property of it for simplex codes (Fig. 2).

From Fig. 2 the quantum channel capacity $C$ is almost achieved by simplex codes. 


\title{
2 元線形符号による情報量規準に基づく符号化の量子利得特性
}

\author{
非会員 石田 雄樹* 非会員 宇佐見 庄五** \\ 正員 白田 毅* 正員 内匠逸**
}

\author{
Properties of Quantum Gain of Coding with Information Criterion \\ by Binary Linear Codes
}

Yuki Ishida*, Non-member, Shogo Usami**, Non-member, Tsuyoshi Sasaki Usuda*, Member, Ichi Takumi***, Member

In quantum information theory, there is superadditivity in capacity of a quantum channel as special property. We showed the calculating method of mutual information analytically for binary linear codes by using Square-root measurement as decoding process. Therefore, many examples of codes which shows existence of superadditivity in capacity have been given. But the scope of method was not clarified. In the present paper, we show the method can be applied to any binary linear codes. Moreover, we show quantum channel capacity is almost attained in finite codeword length by using approximation to simplex code.

キーワード：量子情報理論，量子通信路容量，超加法性，Square-root measurement，符号化の量子利得

Keywords: Quantum information theory, Quantum channel capacity, Superadditivity, Square-root measurement, Quantum gain by coding

\section{1. はじめに}

量子情報理論には，従来の理論にはない通信路容量の超 加法性が存在する ${ }^{(1)(2)}$ 。通常，通信路を 2 回利用したとき， 伝送できる情報量は，1 回利用時の高々 2 倍であるが , 超 加法性により，2 倍を超えより多くの情報量を伝送するこ とができる。すなわち, 通信路容量の超加法性とは, 情報 源の拡大による本質的な伝送情報量の増大からくると考え られる。

近年, 超加法性の明快な例として, 2 元純粋状態信号系 に対し，有限の符号長で超加法性を示す符号が存在するこ とが例示された ${ }^{(3)(4)}$ 。しかし，いくら符号化を工夫しても , 復号過程を個別復号に制限した場合には, 古典情報理論と 同樣となり，超加法性を引き起こすことは不可能である。 超加法性が生ずるためには, 復号過程にエンタングルメン 卜を用いる，量子一括測定（あるいはエンタングルメント 測定) が不可欠である。文献(3) では，さらに，たとえ復

* 愛知県立大学, 愛知県長久手町熊張

Aichi Prefectural University, Kumabari, Nagakute-cho, Aichi 480-1198, Japan

** 名城大学, 名古屋市天白区塩釜口

Meijo University, Shiogamaguchi, Tenpaku-ku, Nagoya 4688502, Japan

*** 名古屋工業大学, 名古屋市昭和区御器所町

Nagoya Institute of Technology, Gokiso-cho, Showa-ku, Nagoya 466-8555, Japan
号過程にエンタングルメントを用いたとしても，情報源の $n$ 次拡大によって得られる記号系列をすべて等確率で利用 した場合には，伝送情報量の増大は得られないことが示さ れている。このことは, 情報量の増大には, 情報源の $n$ 次 拡大から記号系列を選抜することも不可欠であることを意 味する。記号系列の選抜は，符号化と等価であるため，通 信路容量の超加法性に起因する情報量の増大を，(情報量規 準による) 符号化の量子利得と呼ぶ。

通常, 符号化は, 復号誤り率を小さくするために行われ るが, 量子通信路容量の超加法性に注目した場合の議論で は, 情報量を評価する。復号過程にエンタングルメントと いう量子特有の効果を利用しなければ，情報量は増大しな いため，この情報量の増大は，単に符号化利得というので はなく，“量子利得”と呼ばれるのである。

さらに, 近年，この超加法的量子利得を実証する原理実 験が, (独) 情報通信研究機構 (旧通信総合研究所) におい て，世界で初めて実験的に実証された ${ }^{(5)}$ 。の実験 では， 単一光子系による線形従属信号が用いられたが, 今後, 原 理実験を超えて超高速・超高信頼度量子通信の実用化に向 かうためには, 線形独立信号である, コヒーレント状態系 を考えなければならない。しかし，線形独立系は，もつと も簡単な 2 元信号についても, 量子利得と符号の構造の関 係など，弚の樣々な性質が十分に明らかにされるには至っ ておらず，かつ，これまでに示された例における量子利得 の量は極めて少なく，多くは符号化なしの 1.1 倍程度まで 
であった。これは, 量子一括測定による相互情報量を具体 的な符号に対して求める際に, 行列の固有值, 固有べク卜 ル問題を解く必要があることに起因すると考えられる。

最近，我々は, 復号過程として Square-root measurement $(\mathrm{srm})$ を用いたとき, 信号の群共変性 ${ }^{(6)}$ に着目する ことにより, 解析的に相互情報量を求める手法を与えた ${ }^{(7)}$ 。 この手法は，一般の 2 元線形符号に適用できることが予想・ 期待されたが, 文献 (7) では, 単一パリティ検査符号に適 用できることは示されているものの，谷の適用範囲につい ては明確にされていなかった。

本論文では, 文献 (7) の手法が任意の 2 元線形符号に対 する相互情報量の解析解を与えることを証明する。また， $\mathrm{BCH}$ 符号や午の拡大符号の一部に対して , 相互情報量の 解析解をさらに簡単化し，符号長が $10^{10}$ 程度までの長い符 号長に対する量子利得の達成度について考察する。さらに， シンプレックス符号の相互情報量の解析解に対して近似を 用いることで， $10^{300}$ 程度の極めて長い符号長に対する量 子利得特性について考察し，ほぼ量子通信路容量が達成さ れることを示す。

以下, 特に断りのない場合, $\log$ の底は 2 とする。

\section{2. 量子通信路容量の超加法性と相互情報量}

〈2: 1〉 量子通信路容量の超加法性 ここでは, 古典 情報を量子通信路によって伝送するモデルを扱う。 $\{i \mid i=$ $0,1, \cdots, M-1\}$ を古典的情報源のアルファベットとし，光 の先験確率を $\left\{\xi_{i}\right\}$ とする。古典入力情報 $i$ には量子状態 (信号) $\hat{\rho}_{i}$ が 1 対 1 に対応し，これを量子測定することに より古典出力情報 $j$ が出力される。一般に, 古典入出力 情報は 1 対 1 に対応せず, 量子測定過程は杂隹音のある通信 路とみなすことができる。この通信路は以下の条件付確率 $P(j \mid i)$ によって特徵づけられる。

$$
P(j \mid i)=\operatorname{Tr} \hat{\rho}_{i} \hat{\Pi}_{j}
$$

ここで，\{ $\left\{\hat{\Pi}_{j}\right\}$ は量子測定過程を表し，決定作用素と呼ば れる。 $P(j \mid i)$ は, $i$ を送信したときに $j$ と決定される確率 であり，これによって，従来の情報理論と同樣に相互情報 量が定義される：

$$
I(X ; Y)=\sum_{i} \xi_{i} \sum_{j} P(j \mid i) \log \left[\frac{P(j \mid i)}{\sum_{k} \xi_{k} P(j \mid k)}\right]
$$

式 (2) を信号の量子測定過程と先験確率に関して最大化し たものが, 符号長 1 の通信路容量（あるいは符号化なしの 最大相互情報量) $C_{1}$ である ${ }^{(8)(9)}$ 。

$$
C_{1}=\max _{\left\{\xi_{i}\right\}} \max _{\left\{\hat{\Pi}_{j}\right\}} I(X ; Y)
$$

同樣に，情報源の $n$ 次拡大に対し符号長 $n$ の通信路容量 (あるいは符号長 $n$ の最大相互情報量) が定義される。

通信路容量の超加法性は, 符号長 $n$ の量子通信路の容量 を $C_{n}$ として,

$$
C_{n}+C_{m} \leq C_{n+m}
$$

という式で表される。厳密には, 上式で不等号が成立する 状況が存在すれば, 超加法性が存在するとみなされる。光 して, 量子通信路符号化定理によると, 誤りなしの最大伝 送速度 $C$ は以下の極限值

$$
C=\lim _{n \rightarrow \infty} \frac{1}{n} C_{n}
$$

となり，これを量子通信路容量と呼ふ引 ${ }^{(2)}$ 。

さて, 通信路容量の超加法性は, 最も簡単には, $n C_{1}<$ $C_{n}$ であれば存在すると考えてよい。これまでに示されて いる超加法性の例 (3) (4) (10) では, 全て

$$
C_{1}<I_{n}(X ; Y) / n \leq C_{n} / n
$$

の左側の不等号が成立する例が示されている。 $I_{n}(X ; Y) / n-$ $C_{1}$ は, $C_{n} / n-C_{1}$ の下界であり，従って,$I_{n} / n-C_{1}>0$ は， $C_{n} / n-C_{1}>0$, すなわち, 厳密な超加法性を意味している ことがわかる。従って, 本論文では, 以降, $I_{n}(X ; Y) / n-C_{1}$ を量子利得と呼ぶことにする。最大の量子利得は $C-C_{1}$ であ るため, 特定の符号による実際の量子利得 $I_{n}(X ; Y) / n-C_{1}$ と最大の量子利得を比較することは, 意味があると考えら れる。

\section{〈2. 2〉 Square-root measurement による相互情報} 量量子通信路容量の超加法性を示すためには, 適当な 符号化と復号化を行わなければならない。ここでは，これ までの超加法性の例示の研究 ${ }^{(3)}{ }^{(4)}$ に倣い，符号化を適当 な符号語の選抜により行い(選抜された符号語の先験確 率は等確率を仮定する), 復号化には Square-root measurement ( srm) を用いることとする。 srm は, 任意の 2 元線形符号に対して, 誤り率を最小とする復号過程であ る (3)(11)。さて, 先験確率が等確率の $M$ 元の純粋状態信 号系 $\left\{\left|\psi_{i}\right\rangle \mid i=0,1, \cdots, M-1\right\}$ に対し，この $\operatorname{srm}$ は， $\left\{\hat{\Pi}_{j}^{(\mathrm{srm})}=\left|\mu_{j}\right\rangle\left\langle\mu_{j}|| j=0,1, \cdots, M-1\right\}\right.$ である。こ こで, 測定量子状態 $\left\{\left|\mu_{j}\right\rangle\right\}$ は以下のように定義される。

$$
\left|\mu_{j}\right\rangle=\left(\sum_{i=0}^{M-1}\left|\psi_{i}\right\rangle\left\langle\psi_{i}\right|\right)^{-\frac{1}{2}}\left|\psi_{j}\right\rangle
$$

文献 (12) によれば, 信号 $\left|\psi_{i}\right\rangle$ と測定量子状態 $\left|\mu_{j}\right\rangle$ との 内積は，この信号系のグラム行列 $\Gamma=\left[\left\langle\psi_{i} \mid \psi_{j}\right\rangle\right]$ の平方根 の $i$ 行 $j$ 列要素に等しい。

$$
\left\langle\psi_{i} \mid \mu_{j}\right\rangle=(\Gamma)_{i, j}^{\frac{1}{2}}
$$

従って, srm を適用した場合の通信路行列は

$$
P(j \mid i)=\left|\left\langle\psi_{i} \mid \mu_{j}\right\rangle\right|^{2}=\left|(\Gamma)_{i, j}^{\frac{1}{2}}\right|^{2}
$$

となる。

さて , 2 元のレター状態 $\{|0\rangle,|1\rangle\}$ から符号長 $n$ の符号 語状態を構成し，谷の中から $2^{k}$ 個の符号語を選抜してで きる符号を考える。このとき, グラム行列の各成分は, レ 
ター状態の内積 $\kappa=\langle 0 \mid 1\rangle$ と，対応する古典符号の符号語 間のハミング距離 $d_{\mathrm{H}}\left(\psi_{i}, \psi_{j}\right)$ を用いて，以下のように表さ れる。

$$
\left(\Gamma_{2^{k}}\right)_{i, j}=\left\langle\psi_{i} \mid \psi_{j}\right\rangle=\kappa^{d_{\mathrm{H}}\left(\psi_{i}, \psi_{j}\right)} .
$$

一方，srm を適用したときの相互情報量は，通信路行列 を用いて以下のようになる。

$$
\begin{aligned}
I_{n}(X ; Y)= & \frac{1}{2^{k}} \sum_{i=0}^{2^{k}-1} \sum_{j=0}^{2^{k}-1} P(j \mid i) \\
& \times\left\{\log \left[\frac{P(j \mid i)}{\sum_{l=0}^{2^{k}-1} P(j \mid l)}\right]+k\right\} \cdots
\end{aligned}
$$

しかし , グラム行列の固有值 , 固有べクトルを求める困難 さは変わっておらず, 依然としてグラム行列の平方根行列 を求める計算は, 元の数が多いと困難である。

\section{2 元線形符号の相互情報量の解析解}

〈3. 1〉 相互情報量の解析解の導出 ここでは, 文献 (7) に示されている, srm を用いたときの相互情報量の公式が， 任意の 2 元線形符号に対して適用できる一般式であること を示す。文献 (7) では, 公式が適用されるのは, 文献中の 条件式 (29) が満たされたときとされ，条件を満たす例とし て, 単一パリティ検査符号か学げられていた。本論文では, 文献 (7) とは別の手法で, 公式の適用範囲を考察する。

2 元のレター状態 $\{|0\rangle,|1\rangle\}$ から符号長 $n$ の符号語状態 を構成し，弚の中から $M=2^{k}$ 元を選抜したとき，対応す る古典符号か線形符号を構成する場合を考える。このとき， 線形符号の群共变性から $\mathrm{srm}$ による相互情報量 $I_{n}(X ; Y)$ は, 以下のようになる ${ }^{(7)}$ 。

$$
I_{n}(X ; Y)=k+\sum_{j=0}^{2^{k}-1} P(j \mid 0) \log P(j \mid 0)
$$

よって相互情報量は, 通信路行列の 0 行目 $P(j \mid 0)$, すなわ ち, グラム行列の平方根の 0 行目 $\left(\Gamma_{2^{k}}\right)_{0, j}^{\frac{1}{2}}$ を計算すれば求 めることができる。更に, グラム行列の平方根の 0 行目に 対し, 以下の公式が成立する。

$$
\begin{aligned}
\left(\Gamma_{2^{k}}\right)_{0, j}^{\frac{1}{2}}= & \frac{1}{2^{k}} \sum_{k^{\prime}=0}^{2^{k}-1}(-1)^{w_{\mathrm{H}}\left(j \cdot k^{\prime}\right)} \\
& \times \sqrt{\sum_{l=0}^{2^{k}-1}(-1)^{w_{\mathrm{H}}\left(k^{\prime} \cdot l\right)}\left(\Gamma_{2^{k}}\right)_{0, l} \ldots \ldots}
\end{aligned}
$$

ここで $w_{\mathrm{H}}(i)$ は $i$ を 2 進数で表したときのハミング重み を表す。したがって，1 つ目は $j$ と $k^{\prime}, 2$ つ目は $k^{\prime}$ とl の, 兴れ光れ 2 進数表現に論理積演算を行った結果中の 1 のビット数を示している。

命題 1:

式 (13) は任意の 2 元線形符号に対して ,グラム行列の平方 根の解析解である。
補助定理 1: 排他的論理和演算 $\oplus$ をもつ群に関して共変 な信号のグラム行列 $\left(\Gamma_{2^{k}}\right)$ の固有値 $\lambda_{j}$ と固有ベクトル $\boldsymbol{\lambda}_{j}$ は以下の式で与えられる。ただし $, j=0,1, \cdots, 2^{k}-1 て ゙$ ある。

$$
\begin{gathered}
\lambda_{j}=\sum_{l=0}^{2^{k}-1}(-1)^{w_{\mathrm{H}}(j \cdot l)}\left(\Gamma_{2^{k}}\right)_{0, l} \cdots \\
\lambda_{j}=\frac{1}{\sqrt{2^{k}}}\left[\begin{array}{c}
(-1)^{w_{\mathrm{H}}(0 \cdot j)} \\
(-1)^{w_{\mathrm{H}}(1 \cdot j)} \\
\vdots \\
(-1)^{w_{\mathrm{H}}\left\{\left(2^{k}-1\right) \cdot j\right\}}
\end{array}\right]
\end{gathered}
$$

証明: 証明のためには固有值方程式

$$
\Gamma_{2^{k}} \boldsymbol{\lambda}_{j}=\lambda_{j} \boldsymbol{\lambda}_{j}
$$

を示せば十分である。まず，排他的論理和演算 $\oplus$ をも群 に関して共変な信号のグラム行列から, 列ベクトル $\Gamma_{2^{k}} \boldsymbol{\lambda}_{j}$ の $i$ 行成分は，

$$
\begin{aligned}
& \frac{1}{\sqrt{2^{k}}} \sum_{l=0}^{2^{k}-1}(-1)^{w_{\mathrm{H}}(l \cdot j)}\left(\Gamma_{2^{k}}\right)_{0, l \oplus i} \\
= & \frac{1}{\sqrt{2^{k}}} \sum_{l^{\prime}=0}^{2^{k}-1}(-1)^{w_{\mathrm{H}}\left\{\left(i \oplus l^{\prime}\right) \cdot j\right\}}\left(\Gamma_{2^{k}}\right)_{0, l^{\prime}}
\end{aligned}
$$

となる。

一方，列ベクトル $\lambda_{j} \boldsymbol{\lambda}_{j}$ の $i$ 行成分は，

$$
\begin{aligned}
& \frac{1}{\sqrt{2^{k}}} \sum_{l=0}^{2^{k}-1}(-1)^{w_{\mathrm{H}}(j \cdot l)}\left(\Gamma_{2^{k}}\right)_{0, l}(-1)^{w_{\mathrm{H}}(i \cdot j)} \\
= & \frac{1}{\sqrt{2^{k}}} \sum_{l=0}^{2^{k}-1}(-1)^{w_{\mathrm{H}}(j \cdot l)+w_{\mathrm{H}}(i \cdot j)}\left(\Gamma_{2^{k}}\right)_{0, l} \\
= & \frac{1}{\sqrt{2^{k}}} \sum_{l=0}^{2^{k}-1}(-1)^{w_{\mathrm{H}}\{(i \oplus l) \cdot j\}}\left(\Gamma_{2^{k}}\right)_{0, l} \ldots \cdots \cdots
\end{aligned}
$$

となる。

式 (17)(18)より，式 (16) が成立する。

この固有值 , 固有べクトルによってグラム行列の平方根 を計算するためには, 各固有ベクトルが正規直交化されて いなければならない。式 (14) の固有值は一般に縮退がある と考えられる。しかし, 式 (15) の固有べクトルは互いに直 交し，かつ正規化されている。

補助定理 2: 式 (15) の固有ベクトルは正規直交化されて いる。

証明:

$$
\begin{aligned}
\boldsymbol{\lambda}_{j} \cdot \boldsymbol{\lambda}_{j^{\prime}} & =\frac{1}{2^{k}} \sum_{l=0}^{2^{k}-1}(-1)^{w_{\mathrm{H}}(l \cdot j)+w_{\mathrm{H}}\left(l \cdot j^{\prime}\right)} \\
& =\frac{1}{2^{k}} \sum_{l=0}^{2^{k}-1}(-1)^{w_{\mathrm{H}}\left\{l \cdot\left(j \oplus j^{\prime}\right)\right\}} \ldots
\end{aligned}
$$


ここで $j=j^{\prime}$ のとき, $j \oplus j^{\prime}=0$ より，

$$
\begin{aligned}
\boldsymbol{\lambda}_{j} \cdot \boldsymbol{\lambda}_{j^{\prime}} & =\frac{1}{2^{k}} \sum_{l=0}^{2^{k}-1}(-1)^{w_{\mathrm{H}}(0)} \\
& =\frac{1}{2^{k}} \times 2^{k}=1 \cdots \cdots
\end{aligned}
$$

よって , 固有ベクトルは正規化されている。

一方,$j \neq j^{\prime}$ のとき $j^{\prime \prime}=j \oplus j^{\prime} \neq 0$ となる。このとき , $j^{\prime \prime}$ の 2 進数表現には, 0 でないビットが少なくとも 1 つは 存在することになる。今， $u$ 番目のビットが 0 でない (す なわち 1 である) とする。ある $2^{k}-1$ 以下の非負整数 $v$ を $k$ ビットで 2 進数表現したとき, $u$ 番目のビットが 0 であ るならば , $v+2^{u}$ の $u$ 番目のビットは 1 となる。このとき

$$
\begin{aligned}
& =(-1)^{w_{\mathrm{H}}\left(v \cdot j^{\prime \prime}\right)}+(-1)^{w_{\mathrm{H}}\left\{\left(v+2^{u}\right) \cdot j^{\prime \prime}\right\}} \\
& =(-1)^{w_{\mathrm{H}}\left(v \cdot j^{\prime \prime}\right)}+(-1)^{w_{\mathrm{H}}\left\{\left(v \cdot j^{\prime \prime}\right)+1\right\}} \\
& =(-1)^{w_{\mathrm{H}}\left(v \cdot j^{\prime \prime}\right)}-(-1)^{w_{\mathrm{H}}\left(v \cdot j^{\prime \prime}\right)}=0
\end{aligned}
$$

である。また，任意の $2^{k}-1$ 以下の非負整数は, $k$ ビット の 2 進数表現したとき, 必ず $u$ ビット目のみが異なるペア が存在する。したがって，

$$
\begin{aligned}
\boldsymbol{\lambda}_{j} \cdot \boldsymbol{\lambda}_{j^{\prime}}= & \frac{1}{2^{k}} \sum_{l=0}^{2^{k}-1}(-1)^{w_{\mathrm{H}}\left(l \cdot j^{\prime \prime}\right)} \\
= & \frac{1}{2^{k}}\left\{\sum_{l \cdot 2^{u}=0}(-1)^{w_{\mathrm{H}}\left(l \cdot j^{\prime \prime}\right)}\right. \\
& \left.+\sum_{l \cdot 2^{u} \neq 0}(-1)^{w_{\mathrm{H}}\left(l \cdot j^{\prime \prime}\right)}\right\}=0 \ldots \ldots .
\end{aligned}
$$

となり, 異なる固有ベクトルは互いに直交している。

以上より式 (12)(13) は, 排他的論理和演算 $\oplus$ を持つ群 に関して共変な符号の相互情報量の解析解である。ここで, 排他的論理和演算 $\oplus$ を持つ群に関して共変な信号は, 2 元 線形符号を構成するので(6)，命題 1 は真である。

なお，式 (13)の右辺の平方根の中身は, グラム行列の固 有值产のものであるが, グラム行列が正定值であることか ら非負であることを付記しておく。

\section{〈3.2〉 量子擬巡回符号}

〈3. 2: 1 > 量子擬巡回符号 式 (12)(13) の相互情報量 の解析解は, 対応する古典符号が 2 元線形符号であれば適 用できる。乥こで, 2 元の擬巡回符号を考える。 $G(x)$ を生 成多項式， $A_{i}(x)$ を $i$ の 2 進表現に対応する重みを持つ多項 式としたとき，符号長 $n$ の $i$ 番目の符号語多項式 $W_{i}(x)$ を,

$$
\begin{aligned}
W_{i}(x)= & A_{i}(x) G(x) \\
= & w_{i, n-1} x^{n-1}+w_{i, n-2} x^{n-2} \\
& +\cdots+w_{i, 1} x+w_{i, 0} \cdots \cdots
\end{aligned}
$$

とする。ここで $w_{i, k} \in\{0,1\}$ であるのでこれに対応する 量子符号語は, $\left|w_{i, k}\right\rangle \in\{|0\rangle,|1\rangle\}$ として

$$
\left|\psi_{i}\right\rangle=\left|w_{i, n-1}\right\rangle\left|w_{i, n-2}\right\rangle \cdots\left|w_{i, 1}\right\rangle\left|w_{i, 0}\right\rangle \cdots \cdots
$$

となり，量子擬巡回符号が構成できる。擬巡回符号は線形

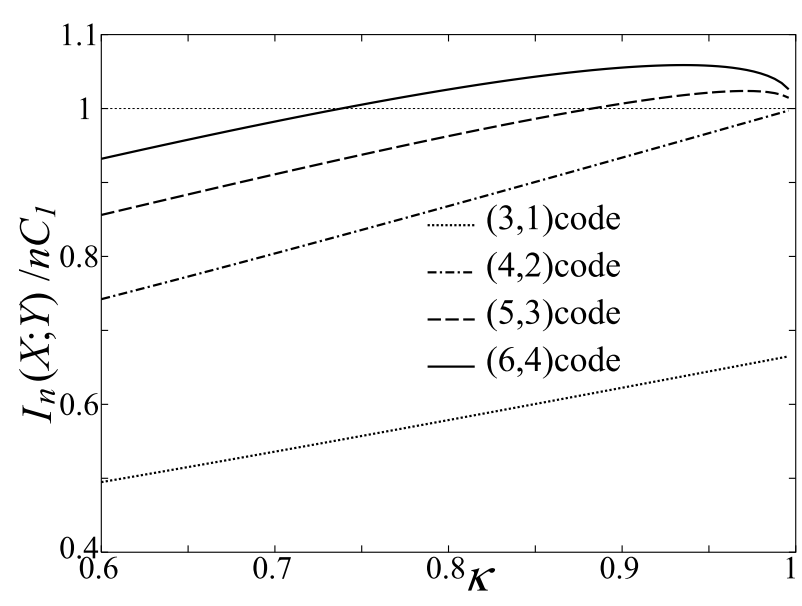

図 1 生成多項式 $G(x)=x^{2}+1$ を持つ符号の相 互情報量の 1 記号あたりの $C_{1}$ 比

Fig. 1. The ratios of mutual information per letter for the code which is constructed by generator polynomial $G(x)=x^{2}+1$ to the channel capacity without coding $C_{1}$ as functions of $\kappa$.

符号であるから, 前節の解析解によって相互情報量が計算 できる。生成多項式 $G(x)$ の次数が $m$ のとき, 符号語の数 は $2^{n-m}$ 個であり， $(n, n-m)$ 符号が構成できる。また $G(x)=1$ とすれば，符号語の選抜を行わないことになる。 このとき，符号長に関わらず， 1 記号当りの相互情報量は符 号化なしの量子通信路容量 $C_{1}$ に一致する。 $G(x)=x+1$ とすれば，符号長 $n$ に対し， $(n, n-1)$ 単一パリティ符号 に相当する量子符号となり，さらに簡略化した解析解と光 の特性が得られている ${ }^{(7)}$ 。2 次以上の生成多項式に相互情 報量の解析解を適用したところ, 符号化効率の悪い一部を 除き，多くの擬巡回符号が量子利得を持ち，超加法性を示 す例となりうることがわかった (図 1)。

〈3. 2. 2〉 擬巡回符号の分割と相互情報量 古典擬巡回 符号では, 生成多項式によっては, より次数の低い生成多項 式からなる複数の符号に分割できる場合がある。このよう な符号に対応する量子擬巡回符号では, 復号過程に Squareroot measurement を用いたときの相互情報量は, 分割後 の符号に相当する量子符号の相互情報量の和となる。この ため，多くの符号の相互情報量の蓄積という観点からは， 合成してできる符号についてはデータを必要としない。ま た, 合成してできる符号の量子利得の程度は, 合成前のも のと同じであるということは, 長い符号長の最大相互情報 量の下限を与える。同時に，短い符号長の相互情報量の特 性は，符号長の長いものに含まれることになり，符号長が 長ければ長いほど高い量子利得を広い範囲で達成するとい う帰結の根拠となる。

以下に分割可能な古典符号の例を示す。

(1) $G(x)=x^{n}+1$ の場合

$(m+n+1, m+1)$ 擬巡回符号の生成多項式 $G(x)=x^{n}+1(n \leq m)$ の $i$ 番目の符号語 を多項式表現で $W_{i}(x)=A_{i}(x) G(x), \quad A_{i}(x)=$ 
$a_{i, m} x^{m}+\cdots+a_{i, 1} x+a_{i, 0}$ とする。このとき $W_{i}(x)$

は

$$
\begin{aligned}
& W_{i}(x) \\
& =A_{i}(x) G(x) \\
& =a_{i, m} x^{m+n}+\cdots+a_{i, m-n+1} x^{m+1} \\
& +\left(a_{i, m-n}+a_{i, m}\right) x^{m}+\cdots \\
& +\left(a_{i, 0}+a_{i, n}\right) x^{n}+a_{i, n-1} x^{n-1}+\cdots \\
& +a_{i, 1} x+a_{i, 0}=\sum_{j=0}^{n-1} D_{i}^{(j)}(x), \\
& D_{i}^{(j)}(x) \\
& =a_{i, k n+j} x^{(k+1) n+j}+\left(a_{i,(k-1) n+j}+a_{i, k n+j}\right) x^{k n+j} \\
& +\cdots+\left(a_{i, j}+a_{i, n+j}\right) x^{n+j}+a_{i, j} x^{j}, \\
& \text {................ }(26) \\
& k=\left\lfloor\frac{m-j}{n}\right\rfloor
\end{aligned}
$$

とかける。ここで, 各 $D_{i}^{(j)}(x) / x^{j}$ について,$x^{n}=X$ とおくと ,

$$
\begin{aligned}
\frac{D_{i}^{(j)}(X)}{x^{j}} \\
=a_{i, k n+j} X^{k+1}+\left(a_{i,(k-1) n+j}+a_{i, k n+j}\right) X^{k} \\
\quad+\cdots+\left(a_{i, j}+a_{i, n+j}\right) X+a_{i, j} \\
=\left(a_{i, k n+j} X^{k}+a_{i,(k-1) n+j} X^{k-1}\right. \\
\left.\quad+\cdots+a_{i, n+j} X+a_{i, j}\right)(X+1) \cdots(28)
\end{aligned}
$$

となり, $(k+2, k+1)$ 単一パリティ符号となる。以 上より, $G(x)=x^{n}+1$ から生成される擬巡回符号 は, $n$ 個の単一パリティ符号に分割可能である。また， $D_{i}^{(j)}(x) / x^{j}$ の形から, 分割される符号は, 元の符号 の LSD (最下位桁) から $l n+j(l=0,1, \cdots, k+1)$ ビット目を抜き出したものである。

(2) $G(x)=x^{2 n}+x^{n}+1$ の場合

同樣にして , 今度は $G(x)=x^{2 n}+x^{n}+1$ の場合 について考える。

$(m+2 n+1, m+1)$ 擬巡回符号の生成多項式 $G(x)=x^{2 n}+x^{n}+1(n \leq m)$ の $i$ 番目の符号 語を多項式表現で $W_{i}(x)=A_{i}(x) G(x), \quad A_{i}(x)=$ $a_{i, m} x^{m}+\cdots+a_{i, 1} x+a_{i, 0}$ とする。このとき $D_{i}^{(j)}(x)$ を

$$
\begin{aligned}
& D_{i}^{(j)}(x) \\
& =a_{i, k n+j} x^{(k+2) n+j} \\
& +\left(a_{i,(k-1) n+j}+a_{i, k n+j}\right) x^{(k+1) n+j} \\
& +\left(a_{i,(k-2) n+j}+a_{i,(k-1) n+j}+a_{i, k n+j}\right) x^{k n+j} \\
& +\cdots+\left(a_{i, j}+a_{i, n+j}+a_{i, 2 n+j}\right) x^{2 n+j} \\
& +\left(a_{i, j}+a_{i, n+j}\right) x^{n+j}+a_{i, j} x^{j}, \cdots \\
& k=\left\lfloor\frac{m-j}{n}\right\rfloor \text {. }
\end{aligned}
$$

として, 先ほどと同樣に, 各 $D_{i}^{(j)}(x) / x^{j}$ について $x^{n}=X$ とおくと ,

$$
\begin{aligned}
& \frac{D_{i}^{(j)}(X)}{x^{j}} \\
= & a_{i, k n+j} X^{k+2}+\left(a_{i,(k-1) n+j}+a_{i, k n+j}\right) X^{k+1} \\
& +\left(a_{i,(k-2) n+j}+a_{i,(k-1) n+j}+a_{i, k n+j}\right) X^{k} \\
& +\cdots+\left(a_{i, j}+a_{i, n+j}+a_{i, 2 n+j}\right) X^{2} \\
& +\left(a_{i, j}+a_{i, n+j}\right) X+a_{i, j} \\
= & \left(a_{i, k n+j} X^{k}+a_{i,(k-1) n+j} X^{k-1}\right. \\
& \left.+\cdots+a_{i, n+j} X+a_{i, j}\right)\left(X^{2}+X+1\right)
\end{aligned}
$$

となり, 生成多項式 $G(x)=x^{2}+x+1$ から生 成される $(k+3, k+1)$ 符号となる。以上より， $G(x)=x^{2 n}+x^{n}+1$ から生成される擬巡回符号 は, $n$ 個の $(k+3, k+1)$ 符号に分割可能である。

(3) $G(x)=G_{r}(x)^{2}$ の場合

一般に, 2 元体上の多項式は，

$$
[F(x)]^{2}=F\left(x^{2}\right) \text {. }
$$

が成立する。これを用いると， $G(x)=\left[G_{r}(x)\right]^{2}$ の とき, $G(x)$ から生成される擬巡回符号は, $G_{r}(x)$ か ら生成される 2 つ擬巡回符号に分割できる。再帰 的な適用により， $G(x)=\left[G_{r}(x)\right]^{2^{n}}$ のとき， $2^{n}$ 個 の擬巡回符号に分割できる。

〈3. 3〉 特定の符号に対するより簡略化された相互情報

\section{量の解析解}

〈 3. 3· 1〉 単一パリティ符号とシンプレックス符号 単 一パリティ符号に関しては, 式 (13) からさらに簡単化した 解析解が求められている ${ }^{(7)}$ 。このような解析解のさらなる 簡単化のためには，符号のハミング重み分布がわかってお り,かつ，ハミング重みの種類が少ない場合に限られる。 式 (10) から, グラム行列は各符号語間のハミング距離を 用いて求めることができるが, グラム行列の 0 行目の各成 分は, 各符号語と全て 0 の符号語 $00 \cdots 0$ とのハミング距 離, すなわち各符号語のハミング重みから求められる。従つ て , ハミング重みの種類が少ないことは, グラム行列の 0 行目の成分の種類が少ないことに対応する。文献 (3) には, シンプレックス符号の相互情報量の解析解が示されている が, ハミング重み分布が一樣 (ハミング重みが 0 と $\frac{M}{2}$ の 2 種類, すなわちグラム行列の 0 行目の成分の種類が 1 と $\kappa^{M / 2}$ のみ) であるなど特殊な符号の特性を活かしている といえる。

〈3· 3· 2〉 $\mathrm{BCH}$ 符号 上記条件に当てはまる符号と して,$\left(2^{m}-1, m+1\right)$ 符号の解析解の簡単化を試みた。こ の符号は原始 $\mathrm{BCH}$ 符号であり, 任意の $m \geq 2$ で存在す る。誤り訂正能力は大きいが , 符号長が長くなると極端に 符号化効率が悪くなる。この符号のハミング重み分布は常 に, $2^{m-1}-1$ と $2^{m-1}$ が $2^{m}-1$ 個ずつ, 0 と $2^{m}-1$ が 
1 個の 4 種類である。相互情報量は以下のようになる:

$$
\begin{aligned}
& I_{2^{m}-1}(X ; Y) \\
&=m+1+f_{0}(\kappa) \log f_{0}(\kappa)+\left(2^{m}-1\right)\left\{f_{1}(\kappa) \log f_{1}(\kappa)\right. \\
&+\left.f_{2}(\kappa) \log f_{2}(\kappa)\right\}+f_{3}(\kappa) \log f_{3}(\kappa) \cdots \cdots(33) \\
& f_{0}(\kappa)=\left\{\frac { 1 } { 2 ^ { m + 1 } } \left[r_{0}(\kappa)+\left(2^{m}-1\right) r_{1}(\kappa)\right.\right. \\
&\left.\left.+\left(2^{m}-1\right) r_{2}(\kappa)+r_{3}(\kappa)\right]\right\}^{2} \\
& f_{1}(\kappa)=\left\{\frac{1}{2^{m+1}}\left[r_{0}(\kappa)+r_{1}(\kappa)-r_{2}(\kappa)-r_{3}(\kappa)\right]\right\}^{2} \\
& f_{2}(\kappa)=\left\{\frac{1}{2^{m+1}}\left[r_{0}(\kappa)-r_{1}(\kappa)+r_{2}(\kappa)-r_{3}(\kappa)\right]\right\}^{2} \\
& f_{3}(\kappa)=\left\{\frac { 1 } { 2 ^ { m + 1 } } \left[r_{0}(\kappa)-\left(2^{m}-1\right) r_{1}(\kappa)\right.\right. \\
&\left.\left.+\left(2^{m}-1\right) r_{2}(\kappa)-r_{3}(\kappa)\right]\right\}^{2} \\
& r_{0}(\kappa)=\sqrt{1+\left(2^{m}-1\right) \kappa^{2^{m-1}-1}+\left(2^{m}-1\right) \kappa^{2^{m-1}}+\kappa^{2^{m}-1}} \\
& r_{1}(\kappa)=\sqrt{1+\left(2^{m}-1\right) \kappa^{2^{m-1}-1}-\kappa^{2^{m-1}}-\kappa^{2^{m}-1}} \\
& r_{2}(\kappa)=\sqrt{1-\left(2^{m}-1\right) \kappa^{2^{m-1}}-1-\kappa^{2^{m-1}}+\kappa^{2^{m}-1}} \\
& r_{3}(\kappa)=\sqrt{1-\left(2^{m}-1\right) \kappa^{2^{m-1}-1}+\left(2^{m}-1\right) \kappa^{2^{m-1}-\kappa^{2^{m}-1}}}
\end{aligned}
$$

〈3. 3. 3〉 $\mathrm{BCH}$ 符号の拡大符号最小ハミング距離 が奇数である 2 元線形符号は, 各符号語に対しパリティ ビットを付加することにより最小ハミング距離を 1 広げ ることができることが知られている。解析解を簡単化した $\left(2^{m}-1, m+1\right)$ 符号は原始 BCH 符号で, かつ, 最小ハ ミング重みは $2^{m-1}-1$ で奇数であり, 上記条件を満足す る。 $\left(2^{m}-1, m+1\right)$ 符号にパリティ検査ビットを付加し てできる， $\left(2^{m}, m+1\right)$ 符号についても簡単化した解析解 を得た。この符号は原始 $\mathrm{BCH}$ 符号の拡大符号であり，任 意の整数 $m \geq 2 \quad(m=2$ のときは単なる $(4,3)$ パリティ 符号) で存在する。ハミング重み分布は $2^{m-1}$ が $2^{m+1}-2$ 個，0 と $2^{m}$ が 1 個ずつの 3 種類となり，従って最小ハミ ング距離は $2^{m-1}$ である。この符号の相互情報量は以下の ようになる:

$$
\begin{aligned}
& I_{2^{m}}(X ; Y) \\
& \begin{aligned}
= & m+1+f_{0}(\kappa) \log f_{0}(\kappa) \\
\quad & +\left(2^{m+1}-2\right) f_{1}(\kappa) \log f_{1}(\kappa)+f_{2}(\kappa) \log f_{2}(\kappa)
\end{aligned}
\end{aligned}
$$

$$
\begin{aligned}
& f_{0}(\kappa)=\left\{\frac{1}{2^{m+1}}\left[r_{0}(\kappa)+2^{m} r_{1}(\kappa)+\left(2^{m}-1\right) r_{2}(\kappa)\right]\right\}^{2} \\
& f_{1}(\kappa)=\left\{\frac{1}{2^{m+1}}\left[r_{0}(\kappa)-r_{2}(\kappa)\right]\right\}^{2} \\
& f_{2}(\kappa)=\left\{\frac{1}{2^{m+1}}\left[r_{0}(\kappa)-2^{m} r_{1}(\kappa)+\left(2^{m}-1\right) r_{2}(\kappa)\right]\right\}^{2} \\
& r_{0}(\kappa)=\sqrt{1+\left(2^{m+1}-2\right) \kappa^{2^{m-1}}+\kappa^{2^{m}}}
\end{aligned}
$$

$$
\begin{aligned}
r_{1}(\kappa) & =\sqrt{1-\kappa^{2^{m}}} \\
r_{2}(\kappa) & =\sqrt{1-2 \kappa^{2^{m-1}}+\kappa^{2^{m}}}
\end{aligned}
$$

\section{4. 量子利得特性の考察}

〈4 1 1 量子利得の有無に関する考察 量子状態符号 化において，符号語を選抜せず， $n$ 次拡大に対して, $2^{n}$ 個 全てを量子符号語とする符号の相互情報量は, $n C_{1}$ を越え ない。なぜなら，このときの決定作用素の最適化の結果は， 個別測定時の結果と等しくなるからである ${ }^{(3)}$ 。よって符号 語空間の全てを用いる符号，すなわち，もつとも規模の大 きい(あるいは符号語数の多い) 符号では, 最適復号の結 果は, $0 \leq \kappa \leq 1$ の全領域で相互情報量が $C_{1}$ に一致する。 この最適復号を与える測定過程は, 各レターに対する $\mathrm{srm}$ を行った場合の個別測定となる。

次に, 先験確率の等しい 2 元量子信号 $\{|0\rangle,|1\rangle\}$ の $n$ 次 拡大に対して, 量子符号語として，

$$
\begin{aligned}
& \left|\psi_{0}\right\rangle=|0\rangle|0\rangle \cdots|0\rangle \\
& \left|\psi_{1}\right\rangle=|1\rangle|1\rangle \cdots|1\rangle
\end{aligned}
$$

の 2 つのみを選抜してできる符号，すなわち，もつとも規 模の小さい(あるいは符号語数の少ない) 符号を考える。 このとき, グラム行列 $\Gamma_{2}$, 平方根 $\left(\Gamma_{2}\right)^{\frac{1}{2}}$ および通信路行 列は,

$$
\begin{aligned}
& \Gamma_{2}=\left[\begin{array}{cc}
1 & \kappa^{n} \\
\kappa^{n} & 1
\end{array}\right] \\
& \left(\Gamma_{2}\right)^{\frac{1}{2}}=\frac{1}{2}\left[\begin{array}{ll}
\sqrt{1+\kappa^{n}}+\sqrt{1-\kappa^{n}} \sqrt{1+\kappa^{n}}-\sqrt{1-\kappa^{n}} \\
\sqrt{1+\kappa^{n}}-\sqrt{1-\kappa^{n}} \sqrt{1+\kappa^{n}}+\sqrt{1-\kappa^{n}}
\end{array}\right]
\end{aligned}
$$

となる。この場合，通信路行列は対角要素同士と非対角要 素同士が同值となる。すなわち次式となる。

$$
\begin{aligned}
P(i \mid i) & =\frac{1}{2}\left(1+\sqrt{1-\kappa^{2 n}}\right) \ldots \ldots \ldots \ldots \ldots \\
P(j \mid i) & =\frac{1}{2}\left(1-\sqrt{1-\kappa^{2 n}}\right), \quad(i \neq j) \cdots
\end{aligned}
$$

このときの 1 記号あたりの相互情報量 $\frac{1}{n} I_{n}(X ; Y)$ は式 (12) より ,

$$
\begin{aligned}
& \frac{1}{n} I_{n}(X ; Y) \\
= & \frac{1}{n}\left\{1+\sum_{j=0}^{1} P(j \mid 0) \log P(j \mid 0)\right\} \\
= & \frac{1}{2 n}\left\{\left(1+\sqrt{1-\kappa^{2 n}}\right) \log \left(1+\sqrt{1-\kappa^{2 n}}\right)\right. \\
& \left.+\left(1-\sqrt{1-\kappa^{2 n}}\right) \log \left(1-\sqrt{1-\kappa^{2 n}}\right)\right\} \cdots
\end{aligned}
$$

となる。

図 2 は, 符号語数 2 の量子符号について, 拡大次数にあ たる符号長 $n=2,3,4$ のときの 1 記号あたりの相互情報量 


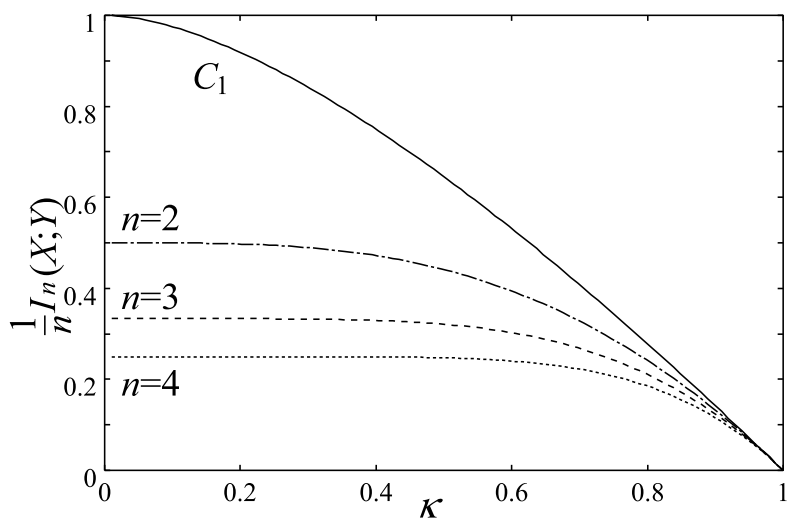

図 2 符号語数 2 の量子符号の 1 記号あたりの 相互情報量と $C_{1}$ の比較

Fig. 2. The mutual information per letter by 2 codewords quantum code (for codeword length $m=$ 2,3 and 4) and $C_{1}$ as functions of $\kappa$.

と，符号長 1 の通信路容量 $C_{1}$ とを比較している。図 2 よ り，拡大次数を大きくして古典符号でいうところの，符号 語間のハミンク距離を増やしていくと，1 記号あたりの相 互情報量は減っていくことがわかる。また式 (38) は，几長 ビット数の全くないとき，すなわち $n=1$ のときに $C_{1}$ と 1 記号あたりの相互情報量は一致することから，符号長 $n$, 符号語数 2 の量子符号では量子利得は得られないことがわ かる。すなわち，次式となる (等号成立は $n=1$ のとき)。

$$
\begin{aligned}
& \frac{1}{n} I_{n}(X ; Y) \\
& =\frac{1}{2 n}\left\{\left(1+\sqrt{1-\kappa^{2 n}}\right) \log \left(1+\sqrt{1-\kappa^{2 n}}\right)\right. \\
& \left.\quad+\left(1-\sqrt{1-\kappa^{2 n}}\right) \log \left(1-\sqrt{1-\kappa^{2 n}}\right)\right\} \\
& \leq C_{1}, \ldots \ldots \ldots \ldots \ldots \ldots \ldots \ldots \ldots \ldots \ldots
\end{aligned}
$$

また , これらの符号を組み合せてできる符号も量子利得を 得られない。この結果，古典符号でいうところの，符号語 間の (最小) ハミング距離は，量子利得に大きな影響を与 えるものの , “最小ハミング距離を大きくすれば大きな量子 利得を得られる”といった, 単純な問題ではないことがわ かる。

符号語数 2 の量子符号は, 量子利得を得ることができな いので, 符号長 3 , 符号語数 4 の単一パリティ符号は, 超加 法性を明示する線形符号のうち最も単純な線形符号である。

他方，以上の 2 つの場合を除く 2 元線形符号は, 生成多 項式や符号化効率によって性質は異なるものの，多くの場 合 , 量子利得がある。

〈 4. 2〉 量子利得の達成度に関する考察 符号長 $n$ の 符号の相互情報量を $I_{n}(X ; Y)$ とすると，

$$
\frac{I_{n}(X ; Y)}{n}>C_{1} \ldots \ldots \ldots \ldots \ldots \ldots \ldots \ldots
$$

のとき, 量子利得があることを示している。我々の究極的

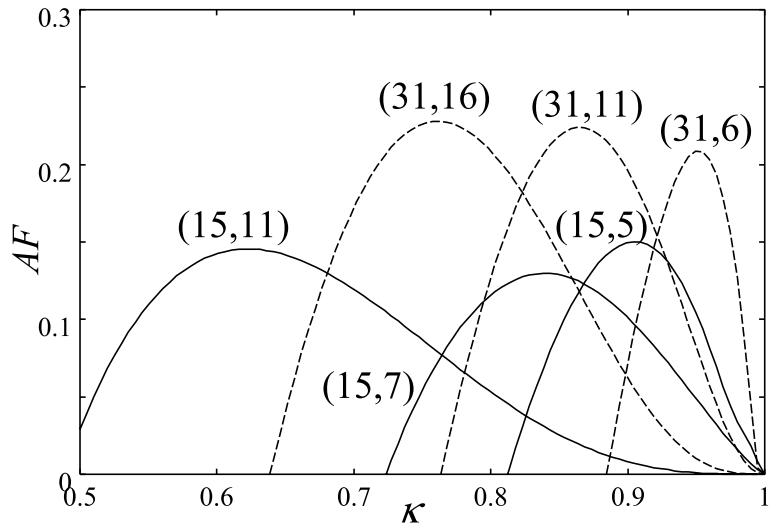

図 3 符号長 15 および 31 の原始 $\mathrm{BCH}$ 符号の 量子利得の達成度

Fig. 3. The achievement factor of quantum gain by primitive $\mathrm{BCH}$ code with codeword length 15 and 31 as functions of $\kappa$.

な目標は, 量子通信路容量 $C$ を達成する符号を構成するこ とであるが，これに至るまでに量子利得の達成度を，

$$
A F=\frac{I_{n}(X ; Y) / n-C_{1}}{C-C_{1}}
$$

と定義する。 $A F=1$ のとき，最大の量子利得が達成され たことを意味する。また，達成度の最大值を符号長に対し，

$$
A F_{\max }=\max _{\kappa} A F \cdots
$$

とする。

これまでに得られた，符号長 127 程度までの $\mathrm{BCH}$ 符号 などの相互情報量においては，同一の符号長の符号では， 達成度の最大值がほぼ同じ水準となる傾向が見られた（図 $3)$ 。こ傾向がより長い符号長の場合でも認められるとす れば，あるクラスの符号に対して達成度の最大值を求める ことには，大きな意義がある。少なくとも，符号長に対す る達成度の下界となる。

$\left(2^{m}-1, m\right)$ シンプレックス符号 , $\left(2^{m}-1, m+1\right) \mathrm{BCH}$ 符号, 帯の拡大符号である $\left(2^{m}, m+1\right)$ 符号について，あ る程度まで详成度の最大值を求めてみた (表 1$)$ 。この結果， 上記 3 種類のいずれの符号でも, 符号長 $2^{30}$ で 3 分の 2 程 度の達成度が得られることがわかった。

〈 4. 3〉 量子利得の達成度の限界特性 我々の興味の 1 つに量子通信路容量への接近の樣子を知ることがある。こ

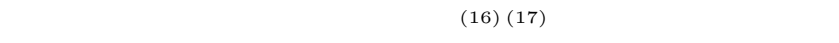
長い符号長までの $A F_{\max }$ を調べたが，より長い符号長の $A F_{\max }$ を調べることは, 達成度の最大值を得る $\kappa$ の值が 非常に 1 に近くなり，相互情報量がごく小さい值になるた め, 困難である。光こで, 前準節で BCH 符号と特性の似 ていたシンプレックス符号に対し, マクローリン展開によ る近似を用いて $A F_{\max }$ の計算を試みた。具体的にはシン プレックス符号の相互情報量の解析解 ${ }^{(3)}$ に以下の近似式を 用いた。 
表 1 シンプレックス符号, $\mathrm{BCH}$ 符号, $\mathrm{BCH}$ 拡 大符号の符号長ごとの量子利得の達成度の最高値 Table 1. The maximum achievement factor of quantum gain by simplex code, $\mathrm{BCH}$ code and extended $\mathrm{BCH}$ code with respect to code scale $m$.

\begin{tabular}{|r||r|r|r|}
\hline$m$ & $\left(2^{m}-1, m\right)$ & $\left(2^{m}-1, m+1\right)$ & $\left(2^{m}, m+1\right)$ \\
\hline \hline 2 & $5.50 \%$ & $0 \%$ & $4.92 \%$ \\
\hline 3 & $10.97 \%$ & $8.45 \%$ & $9.92 \%$ \\
\hline 4 & $16.09 \%$ & $15.01 \%$ & $15.71 \%$ \\
\hline 5 & $20.73 \%$ & $20.87 \%$ & $21.23 \%$ \\
\hline 10 & $38.08 \%$ & $40.16 \%$ & $40.17 \%$ \\
\hline 15 & $49.58 \%$ & $51.46 \%$ & $51.47 \%$ \\
\hline 20 & $57.63 \%$ & $59.04 \%$ & $59.04 \%$ \\
\hline 25 & $63.39 \%$ & $64.42 \%$ & $64.42 \%$ \\
\hline 30 & $67.63 \%$ & $68.21 \%$ & $68.21 \%$ \\
\hline
\end{tabular}

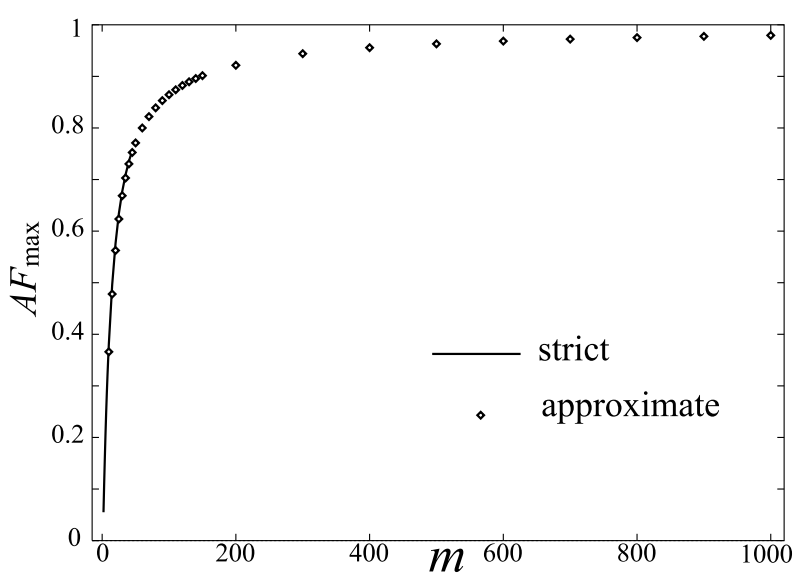

図 4 シンプレックス符号の量子利得の達成度の 最大値

Fig. 4. The maximum achievement factor of quantum gain by simplex code as functions of code scale $m$.

$$
\begin{aligned}
I_{2^{m}-1}(\kappa)= & m+f_{1}(\kappa)^{2} \log f_{1}(\kappa)^{2} \\
& +\left(2^{m}-1\right) f_{2}(\kappa)^{2} \log f_{2}(\kappa)^{2} \ldots(43) \\
f_{1}(\kappa)= & \frac{1}{2^{m}}\left[\alpha(\kappa)+\left(2^{m}-1\right) \beta(\kappa)\right] \\
f_{2}(\kappa)= & \frac{1}{2^{m}}[\alpha(\kappa)-\beta(\kappa)] \\
\alpha(\kappa)= & \sqrt{1+\left(2^{m}-1\right) \kappa^{2^{m}-1}} \\
\approx & \sqrt{M-\frac{M}{2}(M-1) x\left\{1-\frac{1}{2}\left(\frac{M}{2}-1\right) x\right\}} \\
\beta(\kappa)= & \sqrt{1-\kappa^{2^{m}-1}} \\
\approx & \sqrt{\frac{M}{2} x\left\{1-\frac{1}{2}\left(\frac{M}{2}-1\right) x\right\}}
\end{aligned}
$$

ここで，

$$
x=1-\kappa \ll 1
$$

$M=2^{m}$
である。図 4 は, 符号規模を表すパラメタ $m$ (情報記号数 に対応）に対するシンプレックス符号の $A F_{\max }$ の厳密解 および近似解を示している。シンプレックス符号では $m \rightarrow$ 大のとき $x \rightarrow$ 小となり, 近似条件と一致する。近似解は $m>10$ で厳密解とほぼ一致している。 $A F_{\max }$ は符号長 を伸ばすことで, 途中で飽和することなく向上し， $\kappa$ が 1 にごく近い部分で，ほぼ量子通信路容量を達成できること がわかる。シンプレックス符号を用いた場合，パラメタ $m$ が , $m \rightarrow$ 大と変化するにつれ， $A F_{\max }$ を達成する $\kappa$ も， $\kappa \rightarrow 1$ と変化する。これは, シンプレックス符号では, パ ラメタ $m$ により符号長だけでなく，符号化効率も決まって しまうためである。一方，BCH 符号では符号長と符号化効 率はとれ炎れ設計可能である。従って， $\mathrm{BCH}$ 符号により，

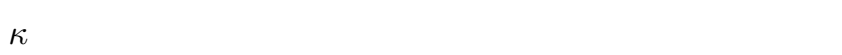
れる。

\section{5. まとめ}

本論文では, 先に示した解析的手法による相互情報量が 任意の 2 元線形符号に対する相互情報量の解析解であるこ とを示した。この解析解を量子擬巡回符号に適用し, 樣々 な符号に対する相互情報量を求め, 谷の特性を示した。ま た, 特定のクラスの符号について, より簡単化された相互 情報量の解析解を示し, 長い符号長に対する量子利得の達 成度についても考察した。これに関連して, シンプレック ス符号の相互情報量にマクローリン展開による近似を導入 し, ごく長い符号の量子利得の達成度の最大值を調べた結 果, 量子利得の達成度は飽和せず, シンプレックス符号で ほぼ量子通信路容量を達成できることがわかった。

より現実に近い状況を考える場合，量子状態は本論文で 扱った純粋状態ではなく，古典杂倠音を含んだ混合状態を考 える必要がある。しかし, 特に, 光ファイバ通信路や宇宙空 間通信路を表す，もつとも重要な量子通信路モデルである 減衰通信路に対し, エネルギー制約条件下での量子通信路 容量が, コヒーレント状態によって達成されることが, 一 昨年に証明され ${ }^{(18)}$, コヒーレント状態の重要性が再認識さ れている。コヒーレント状態は, 減衰してもコヒーレント 状態の性質を維持し，したがって減衰通信路の出力も純粋 状態であることから，純粋状態に限った議論でも，一定の 意義があるといえる。

本論文では, 符号化の量子利得について, 情報量規準の 観点から考察を行なった。しかし，符号化というのは本来， 誤り率を小さくするために行なわれるものであり，今後，誤 り率規準の量子利得特性の考察を行なうことが必要である と考えられる。

謝 辞

本研究の一部は, 総務省の「戦略的情報通信研究開発推 進制度」による研究成果であり, 文科省科研費補助金の助 成を受けた。

(平成 18 年 3 月 14 日受付，平成 18 年 8 月 23 日再受付) 


\section{文献}

(1) A.S. Kholevo: "Information-theoretical aspects of quantum measurement", Problemy Peredachi Informatsii, Vol.9, No.2, pp.31-42 (1973)

(2) A.S. Kholevo: "Capacity of a quantum communication channel", Problemy Peredachi Informatsii, Vol.15, No.4, pp.3-11 (1979)

( 3 ) M. Sasaki, K. Kato, M. Izutsu, and O. Hirota: "Quantum channels showing superadditivity in classical capacity", Phys. Rev., Vol.A58, No.1, pp.146-158 (1998)

(4) K. Kato, M. Osaki, and O. Hirota: "Calculation of mutual information for quantum code words with very long length", in Abst. of Forth International Conference on Quantum Communication, Measurement, and Computing (QCM'98), p.30 (1998)

( 5 ) M. Takeoka, M. Fujiwara, J. Mizuno, and M. Sasaki: 'Implementation of generalized quantum measurements: Superadditive quantum coding, accessible information extraction, and classical capacity limit", Phys. Rev., Vol.A69, 052329 (2004)

(6) T.S. Usuda and I. Takumi: "Group covariant signals in quantum information theory", in Quantum Communication, Computing, and Measurement 2, P. Kumar, G. M. D'Ariano, and O. Hirota (Eds.), Plenum Press, New York, pp.37-42 (2000)

( 7 ) S. Usami, T.S. Usuda, I. Takumi, and M. Hata: IEICE Trans., Vol.E82-A, No.10, pp.2185-2190 (1999)

(8) M. Ban, K. Kurokawa, and O. Hirota: "Cut-off rate performance of quantum communication channels with symmetric states", Quantum and Semiclass. Opt., No.1, pp.206-218 (1999)

(9) M. Osaki, M. Ban, and O. Hirota: "On maximum mutual information without coding", in Quantum Communication, Computing, and Measurement 2, P.Kumar, G.M.D'Ariano, O.Hirota (Eds.), Plenum Press, New York, pp.17-26 (2000)

(10) O. Hirota: "A foundation of quantum channels with super additiveness for Shannon information", Appl. Algebra Engrg. Commun. Comput., Vol.10, pp.401-423 (2000)

(11) T.S. Usuda, I. Takumi, M. Hata, and O. Hirota: "Minimum error detection of classical linear code sending through a quantum channel", Phys. Lett., Vol.A256, pp.104-108 (1999)

(12) P. Hausladen, R. Jozsa, B. Schumacher, M. Westmoreland, and W.K. Wootters: "Classical information capacity of a quantum channel", Phys. Rev., Vol.A54, No.3, pp.1869-1876 (1996)

(13) S. Usami, T.S. Usuda, I. Takumi, R. Nakano, and M. Hata: "Superadditivity in capacity of quantum channel by classical pseudo-cyclic codes", in Quantum Communication, Computing, and Measurement 3, P. Tombesi and O. Hirota (Eds.) Plenum Press, New York, pp.35-38 (2001)

(14) A. Peres and W.K. Wootters: "Optimal detection of quantum information", Phys. Rev. Lett., Vol.66, pp.1119-1122 (1991)

(15) M. Ban, K. Yamazaki, and O. Hirota: "Accessible information in combined and sequential quantum measurement on a binary-state signal", Phys. Rev., Vol.A55, pp.22-26 (1997)

(16) M.V. Burnashev and A.S. Holevo: "On reliability function of quantum communication channel", quant-ph/9703013 (1997)

（17）黑川啓子，広田 修：「量子信頼性関数の特性と炎の種々の量 子信号系への応用」, 信学論 $(A)$, J83-A, pp.57-66 (2000)

(18) V. Giovannetti, S. Guha, S. Lloyd, L. Maccone, J.H. Shapiro, and H.P. Yuen : "Classical capacity of the lossy bosonic channel: The exact solution", Phys. Rev. Lett. Vol.92, No.2, $027902(2004)$

（19）広田 修：「量子情報科学の基礎」，森北出版 (2002)

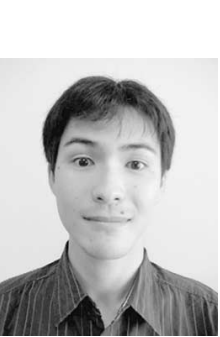

(非会員) 2005 年 3 月愛知県立大学情報科学部 地域情報科学科卒業。現在, 同大大学院博士前期 課程在学中。量子情報理論に関する研究に従事。 電子情報通信学会会員。

宇佐見 庄 五 (非会員) 1997 年名古屋工業大学知能情報シス

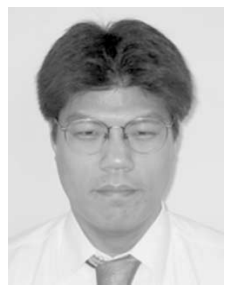
テム学科卒業。2002 年同大大学院博士後期課程 了。同年同大大学院ベンチャービジネスラボラト リ研究員。2004 年より名城大学理工学部情報工 学科講師となり，現在に至る。量子情報理論，符 号理論の研究に従事。博士 (工学)。情報処理学 会会員。

臼田

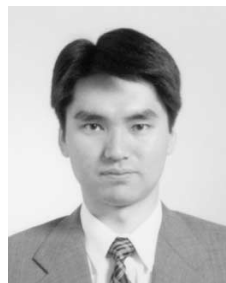

内 匠

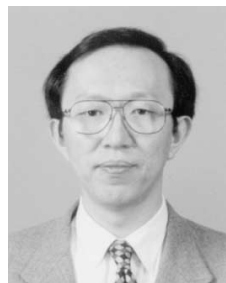

毅 (正員) 1990 年玉川大学工学部情報通信工学科 卒業。1995 年同大大学院工学研究科博士課程了。 同年名古屋工業大学助手。2002 年 4 月より愛知 県立大学情報科学部地域情報科学科助教授となり， 現在に至る。量子情報理論と光の応用に関する研 究に従事。博士 (工学)。電子情報通信学会会員。 